\section{UCP-3: Regulação da Expressão Gênica no Músculo Esquelético e Possível Relação Com o Controle do Peso Corporal}

\section{RESUMO}

As UCPs constituem um subgrupo das proteínas carreadoras mitocondriais que estão localizadas na membrana mitocondrial interna. Por meio da dissipação do gradiente de próton, elas desacoplam a fosforilação oxidativa e convertem combustivel em calor. Foram identificadas quatro isoformas da UCP. A UCP-1 foi a primeira a ser descoberta, sendo encontrada exclusivamente no tecido adiposo marrom, a UCP-2 é encontrada em vários tecidos, a UCP-3 encontra-se no músculo esquelético em humanos e tecido adiposo marrom e músculo esquelético em roedores, enquanto a UCP-4 é expressa no cérebro. A expressão da UCP-3 no músculo esquelético e no tecido adiposo marrom pode fazer destes tecidos importantes mediadores da termogênese adaptativa. No entanto, o papel da UCP-3 quanto ao gasto de energia e como causa da obesidade ainda não passa de uma hipótese. Há evidências de que a UCP-3 seja regulada pelos substratos energéticos, tais como ácidos graxos e glicose que, ao entrarem no músculo, provocam aumento da UCP-3 e aumento no gasto de energia. Nosso objetivo nesta revisão foi descrever e discutir as informações disponíveis sobre a regulação da UCP-3, e sua possível relação com o controle do peso corporal. (Arq Bras Endocrinol Metab 2004;48/3:337344)

Descritores: Proteína desacopladora; Tecido muscular; Exercício físico; Substratos energéticos

\begin{abstract}
UCP-3: Regulation of Genic Expression on Skeletal Muscle and Possible Role on Body Weight Control.

Uncoupling proteins constitute a subgroup of mitochondrial carrier proteins that are located in the inner mitochondrial membrane. By dissipating proton gradients, they act to uncouple respiration from oxidative phosphorylation and convert fuel to heat. Four homologous UCP isoforms have been identified. UCP-1, the first UCP to be described, is found exclusively in brown adipose tissue, UCP-2 in several tissues, UCP-3 in human skeletal muscle and rat brown adipose tissue and skeletal muscle, whereas UCP-4 is expressed in the brain. Expression of UCP-3 in the skeletal muscle and the brown adipose tissue may place these tissues as important mediators for adaptative thermogenesis. However, the role of UCP-3 in energy expenditure and as a cause of obesity has been controversial. There are evidences that UCP-3 can be regulated by energy substrates as fatty acids and glucose, by entering the muscle and stimulating UCP-3 to increase energy expenditure. Our aim in this review was to describe and discuss the available information on UCP-3 regulation and its possible relation with body weight control. (Arq Bras Endocrinol Metab 2004;48/3:337-344)
\end{abstract}

Keywords: Uncoupling protein; Muscle tissue; Physical exercise; Energy substrates revisão

\author{
Tatiane Z. Depievi \\ Roberta R. Pinto \\ Juliana K. Catarin \\ Magda C.L. de Carli \\ Jair R. Garcia Junior
}

Pró-Reitoria de Pesquisa e

Pós-Graduação da UNOESTE (TZD, RRP, JKC, MCLC,

JRGJ), Presidente Prudente, SP; e Universidade Paranaense UNIPAR (TZD, MCLC), Curitiba, PR.

Recebido em 31/01/03

Revisado em 04/08/03 e 16/02/04

Aceito em 24/02/04 
$\mathrm{A}^{\mathrm{s}}$ PROTEÍNAS DESACOPLADORAS (uncoupling proteins - UCP) são membros da família de proteínas carreadoras mitocondriais, que incluem a UCP-1, UCP-2, UCP-3 e UCP-4 (1). A primeira proteína desacopladora foi descoberta por Ricquier e Kader (2). Esta proteína está localizada na membrana mitocondrial interna e, pela dissipação do gradiente de próton da membrana interna da mitocôndria, desacopla a fosforilação oxidativa da síntese de ATP, produzindo apenas calor (3) (figura 1). A UCP-1 está associada com a termogênese do tecido adiposo marrom (TAM) (4) e foi encontrada exclusivamente neste tecido. O TAM está presente em todos os mamíferos pequenos e nos recém-nascidos de mamíferos maiores, inclusive humanos (5). O TAM consiste de células adiposas marrons que são morfologicamente e funcionalmente distintas das células adiposas brancas. As células adiposas marrons contêm gotículas de triglicerídeos e numerosas mitocôndrias caracterizadas por maior desenvolvimento da membrana interna. A termogênese no TAM é ativada em recém-nascidos, em roedores expostos ao frio e em animais que saem da hibernação. Por ser menos abundante em grandes mamíferos adultos, seu papel é menos relevante. A UCP-1 é altamente regulada, sendo sua atividade diminuída por nucleotídeos de purina, difosfato ou trifosfato e aumentada por ácidos graxos (6). (figura 1)

Em 1997, duas novas proteínas desacopladoras foram descobertas: UCP-2 e UCP-3. De natureza similar à UCP-1, a UCP-2 e UCP-3 parecem funcionar como desacopladoras da fosforilação oxidativa, mas com distribuição em tecidos diferentes da UCP-1 (79). A UCP-2 é expressada no músculo esquelético de humanos, coração, placenta, pulmão, fígado, rins, pâncreas e tecido adiposo branco (10). A UCP-3, principalmente no músculo esquelético em humanos e no tecido adiposo marrom e músculo esquelético em roedores (4). Desde que o músculo esquelético e o TAM são considerados importantes locais para o gasto de energia em humanos e roedores, respectivamente, a UCP-3 pode ser um importante mediador da termogênese adaptativa (11).

A UCP-2 e a UCP-3 têm seqüências de aminoácidos altamente homólogas à UCP-1 em comparação com outros membros da família das proteínas carreadoras mitocondriais. Suas identidades são de $55 \%$ e $56 \%$, respectivamente, enquanto a outra proteína carreadora mitocondrial que mais se relaciona com a UCP é a carreadora de 2-oxoglutarato/malato que tem $32 \%$ de identidade. Dois outros carreadores expressados predominantemente no cérebro e mostrando alguma atividade desacopladora foram recentemente identificados e referidos como proteína carreadora mitocondrial cerebral l (BCMPl) ou UCP-4, que é menos similar à UCP-1 (6).

Consideradas descobertas importantes, a clonagem da UCP-2 e UCP-3 tem produzido entusiasmo, devido à hipótese de que, semelhantemente à UCP-1 no TAM, estas UCPs homólogas podem ser mediadoras da termogênese adaptativa em outros tecidos e responsáveis pela oxidação do excesso de energia consumido $(12,13)$. Numa direção um pouco diferente, há estudos demonstrando a importância das UCPs no controle da geração de radicais livres, principalmente quando há aumento dos processos oxidativos mitocondriais $(13,14)$. Desse modo, serão revisadas e dis-
Figura 1. Desenho esquemático dos mecanismos de ressíntese de ATP na fosforilação oxidativa (1) e dissipação de energia pelas proteínas desacopladoras (2). Os hidrogênios liberados das reações catalisadas pelas desidrogenases (linhas pontilhadas) são carreados pelas flavoproteínas na forma reduzida $\left(\mathrm{NADH}+\mathrm{H}^{+}\right.$e $\left.\mathrm{FADH}_{2}\right)$ e bombeados pela cadeia respiratória (CR) para o espaço intermembranas, criando um gradiente de prótons. Devido a esse gradiente, os $\mathrm{H}^{+}$ retornam para a matriz passando pela ATP sintase e ressintetisando ATP ou, alternativamente, passam pela proteína desacopladora (UCP) que dissipa a energia na forma de calor. $A G$ = ácidos graxos; $A D P=$ adenosina difosfato; ATP = adenosina trifosfato; $C K$ = ciclo de Krebs; $\mathrm{MCT}=$ transportador de monocarboxilatos; $\mathrm{Pi}=$ fosfato inorgânico.

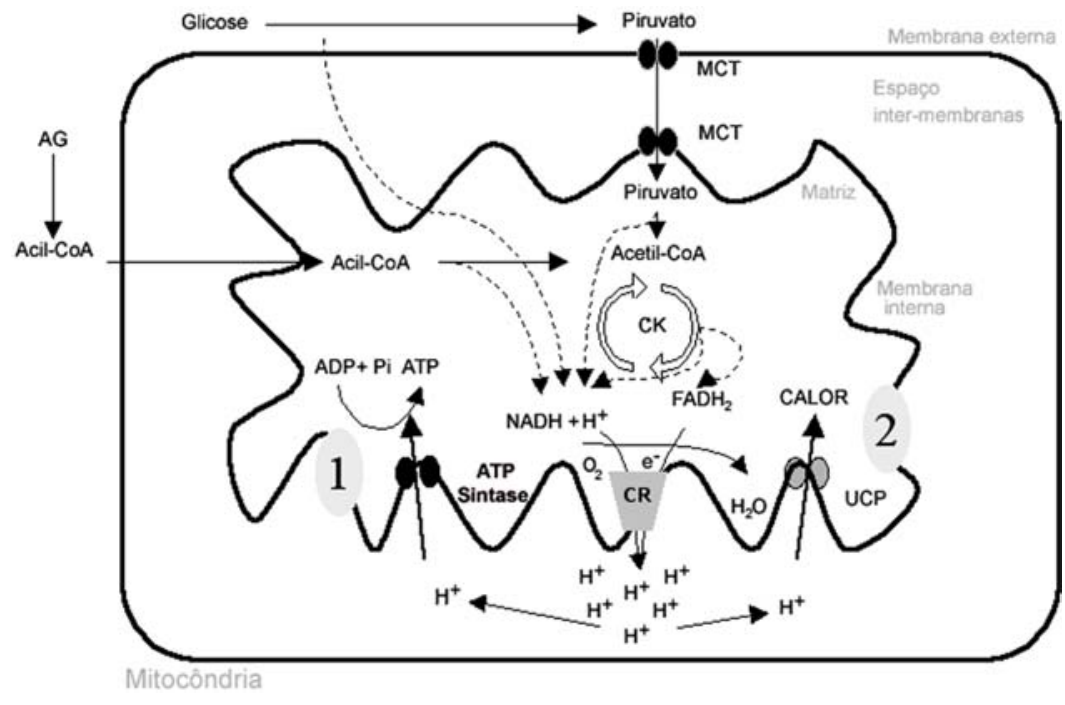


cutidas as funções e a regulação da UCP-3, enfocando seu papel termogênico sob a perspectiva de atuar no controle do peso corporal.

\section{Expressão da UCP-3}

A UCP-3 é expressa preferencial e significantemente no músculo esquelético humano, sendo transcrita nas formas longa e curta, a UCP-3L e a UCP-3S, respectivamente (15). A UCP-3L é uma proteína de 312 aminoácidos e a UCP-3S é uma proteína de 275 aminoácidos, com ausência do último domínio transmembrana (16).

O gene da UCP-3S é programado para codificar uma proteína com falha nos últimos 37 resíduos Cterminais da UCP-3L, sendo gerada quando uma divisão e um sinal de poliadenilação (AATAAA) localizado no último intron terminam prematuramente o alongamento da mensagem (15).

Alguns autores relatam que ambas as transcrições de UCP-3S e UCP-3L são igualmente expressas nos músculos e são coordenadamente reguladas pelo jejum. Mutação genética que impede a síntese da UCP-3L e permite apenas da UCP-3S determina marcante redução da oxidação de gordura e um quociente respiratório elevado, sugerindo que a mudança na proporção UCP-3L/UCP-3S pode ter efeito no metabolismo dos lipídeos (9).

\section{UCP-3 e sua relação com a obesidade}

Devido ao fato de a UCP funcionar como dissipadora da energia (sob a forma de calor) que seria utilizada para ressíntese do ATP, indiretamente ela provoca maior consumo de substratos energéticos. A descoberta de sua presença em uma grande variedade de tecidos, além do tecido adiposo marrom, trouxe grandes perspectivas em relação ao seu possível papel na etiologia da obesidade. Alguns pesquisadores propõem que a UCP funcione como um ciclo fútil de prótons, pois como há diminuição da eficiência da síntese de ATP, ocorre aumento do catabolismo dos nutrientes como forma de manter a repleção do ATP. Mesmo quando só se conhecia a UCP-1, já havia evidências de que a termogênese era deficiente em alguns casos de obesidade em pequenos roedores. Mais recentemente, com o conhecimento das outras duas isoformas dessa proteína, já se estabeleceram relações delas com a obesidade, como, por exemplo, a diminuição da expressão gênica da UCP-2 em músculos abdominais de obesos (12) e a correlação inversa entre expressão gênica da UCP-3 e o índice de massa corporal (17).

O tecido adiposo branco e o muscular esquelético são os dois mais abundantes tecidos corporais, po- rém apenas o tecido muscular desempenha papel significativo na termogênese nos mamíferos adultos. Deste modo, a identificação da UCP-3 produziu um grande interesse, associado com pesquisas sobre obesidade, pois a UCP-3 é constitutivamente expressada no tecido muscular. A idéia de que disfunções na UCP-3 relacionem-se com a obesidade suscitou do mapeamento do gene da UCP-3 no cromossomo 11 de humanos e cromossomo 7 de camundongos, regiões relacionadas com a obesidade e hiperinsulinemia. Ao mesmo tempo, foi demonstrado que a expressão gênica da UCP-3 está diminuída na obesidade, em camundongos obesos com deficiência de leptina e em ratos Wistar obesos com resistência à leptina $(10,18)$.

Alterações extremas na expressão da UCP-2 e/ou UCP-3 têm sido documentadas na obesidade, caquexia e inflamações, sugerindo que a desregulação dessas duas proteínas pode contribuir para estas condições (18).

Em ratos Zucker obesos, foi observada diminuição de $42 \%$ na expressão do RNAm da UCP-3 no TAM e diminuição de $41 \%$ no músculo sóleo, quando comparados com ratos magros (9).

\section{Papel da UCP-3 no músculo esquelético e tecido adiposo marrom}

O papel do TAM na termogênese adaptativa em humanos adultos e a relação de sua função com a etiologia da obesidade humana são inexistentes devido à pequena quantidade desse tecido em humanos. Esta situação está servindo para desviar maior atenção para o músculo esquelético, o qual, pela sua massa (cerca de $40 \%$ do peso corporal), tem sido entendido como o principal local da termogênese adaptativa em grandes mamíferos.

Diferentemente do TAM, os mecanismos básicos da termogênese no músculo esquelético são ainda pobremente compreendidos. No entanto, relatos dos anos 90 de que o fenômeno de escoamento dos prótons pelas mitocôndrias também existe em outros tecidos além do TAM, e que poderia contribuir com pelo menos $50 \%$ da produção de calor, induziram a busca pelas UCPs no músculo esquelético (19). Isto conduziu à descoberta de vários novos membros da família das UCPs (UCP-2 e UCP-3) e a UCP do TAM foi renomeada de UCP-1 (5).

No TAM, a exposição ao frio por 48 horas provoca aumento de 1,5 vezes na expressão do RNAm da UCP-3, sendo este efeito menos pronunciado do que na UCP-1 (aproximadamente 5 vezes). Portanto, a UCP-3 do TAM do rato, que é expressa abaixo de condições basais para aproximadamente o mesmo nível 
da UCP-1, deve contribuir para termogênese, porém menos que a UCP-1 na adaptação ao frio. No músculo esquelético, a exposição por 48 horas ao frio não mudou a expressão do RNAm da UCP-3 no músculo tibial anterior do rato (20). De qualquer modo, um estudo mostrou que a expressão do RNAm da UCP-3 é maior entre 6 e 24 horas de exposição ao frio e diminui depois de 6 dias de adaptação à baixa temperatura; portanto, a UCP-3 pode contribuir para a termogênese sem tremores apenas na resposta aguda à exposição ao frio. No entanto, aumento significativo da UCP-3 foi observado em esquilos durante a hibernação (9). Em humanos expostos ao frio, ocorrem tremores e calafrios para aumentar a produção de calor, estando ainda indefinido o quanto a regulação positiva da UCP-3 no tecido muscular poderia contribuir para a adaptação à baixa temperatura a curto e a longo prazo.

De forma semelhante, o consumo excessivo de alimento provoca, em roedores, aumento da atividade metabólica do TAM por estimulação da UCP-1, para maior dispêndio de energia $(21,22)$, enquanto em humanos há aumento do gasto de energia por termogênese com atividade, mas sem exercício (remexer, manter postura, movimentar espontaneamente), que corresponde ao gasto de aproximadamente 33\% da energia consumida em excesso (23). Infelizmente, ainda não há resposta para o quanto o aumento da expressão gênica e da atividade da UCP-3 pode contribuir para o dispêndio do excesso de energia nestas situações. No estudo de Levile e cols. (23), foi observado gasto de aproximadamente $8 \%$ devido à alteração do gasto energético de repouso, talvez um indicativo do aumento da atividade de proteínas celulares como as UCPs ou $\mathrm{Ca}^{2+-}$ ATPase (SERCA), que libera calor da hidrólise do ATP durante o seqüestro de $\mathrm{Ca}^{2+}$ para o retículo sarcoplasmático (24). O treinamento com exercício físico é uma situação que estimula a expressão gênica das proteínas SERCA na musculatura esquelética (25), tornando mais eficiente o seqüestro de $\mathrm{Ca}^{2+}$ para o retículo sarcoplasmático e, conseqüentemente, o relaxamento muscular. Fica a dúvida se estas proteínas mantêm atividade aumentada também durante o repouso ou apenas durante o exercício, quando são mais requisitadas.

Por outro lado, o jejum por um período de 48 horas diminui a expressão do RNAm da UCP-3 no TAM em 74\%. Portanto, no TAM, a UCP-3 age principalmente em resposta ao frio como uma proteína termogênica (19).

Se, por um lado, o efeito do frio na expressão da UCP-3 parece ser lógico, o efeito do jejum pode ser considerado surpreendente. Um período de 48 horas de jejum aumentou a expressão do RNAm da UCP-3 no músculo sóleo e tibial anterior de ratos, 2 e 6 vezes, respectivamente (19). Em humanos, o mesmo tipo de observação foi relatado (26). No músculo esquelético, a restrição alimentar diminui a expressão gênica da UCP-3 e não altera (13) ou aumenta a expressão gênica da UCP-2 (16). Em sujeitos magros e obesos mantidos com uma dieta hipocalórica $(248 \mathrm{Kcal} / \mathrm{d})$, observa-se grande aumento na expressão da UCP-3 no músculo vasto lateral (27). A razão para o aumento da expressão da UCP-3 nos músculos durante o jejum é difícil explicar. Há uma hipótese de que, durante o jejum, a atividade do TAM é moderada e a atividade da UCP-3 no músculo esquelético aumenta para prevenir uma perigosa diminuição na temperatura corporal $(9,16)$, assim como ocorre em resposta à exposição aguda ao frio e hibernação, quando a UCP-3 age como uma verdadeira proteína termogênica.

\section{Ácidos graxos livres e regulação da UCP-3}

A redução dos triglicerídeos contidos nos músculos esqueléticos pode prevenir o desenvolvimento da diabete mellitus. Para prevenção do acúmulo excessivo do triglicerídeo nos músculos esqueléticos e da obesidade, o papel fisiológico e a regulação da expressão da UCP-3 no músculo esquelético estão sendo extensamente estudados. Estudos têm revelado que a circulação de ácidos graxos livres (AGL) regula a expressão do RNAm da UCP-3 (28). Visto que há uma forte e positiva relação entre a concentração de AGL no sangue e a concentração da UCP-3 nos músculos esqueléticos, o AGL pode ser o mais importante regulador da UCP-3 no músculo esquelético.

O jejum é um estado que causa aumento na concentração e oxidação dos ácidos graxos. No músculo, o jejum causa aumento marcante na expressão do RNAm da UCP-3 em camundongos, ratos e humanos, provavelmente por estímulo da concentração elevada de AGL (26). Observa-se, no jejum, o aumento da expressão do RNAm da UCP-3 no músculo esquelético, o que persiste até a alimentação, quando diminui a concentração de AGL no sangue (13). Em ratos em jejum por 46 horas, a administração de um agente antilipolítico, o ácido nicotínico, que previne completamente o aumento de AGL, há diminuição da expressão do RNAm da UCP-3 no músculo sóleo, enquanto a infusão de heparina provoca aumento da expressão gênica da UCP-3 (26). A expressão do RNAm da UCP-3 no músculo gastrocnêmio foi elevada em ratos que se tornaram diabéticos pelo uso de streptozotocina e tiveram a concentração de AGL no plasma significantemente aumentada. Em humanos, a expressão do 
RNAm da UCP-3 é positivamente correlacionada com a circulação de AGL (28).

Vários estudos mostram que a região 5' do gene da UCP-1 contém um receptor ativado pelo proliferador de peroxisoma (PPAR), que está envolvido na expressão da UCP-1 (26). O músculo esquelético também expressa o PPAR, e a possível existência do elemento resposta PPAR no gene da UCP-3 poderia produzir um mecanismo pelo qual os AGL, que ligam-se ao PPAR, aumentam a expressão da UCP-3 no músculo. Nas células musculares, nas células $\mathrm{C} 2 \mathrm{C} 12$ e nos miotúbulos L6, o AGL e o tratamento com lipídios regularam positivamente a expressão do RNAm da UCP-3 (29). O BRL49653, um ligante para o receptor nuclear de hormônios e para o PPAR, induz a expressão do RNAm da UCP-3 nas células $\mathrm{C} 2 \mathrm{C} 12$, sugerindo que o PPAR pode regular a transcrição do gene da UCP-3 (28).

Além disso, para examinar se a indução do AGL na regulação da UCP-3 foi mediada pela razão AGL/acetil-CoA intracelular ou pelo aumento da $\beta$-oxidação mitocondrial de ácidos graxos, dois estudos foram realizados. A adição do ácido bromopalmítico, um análogo do ácido graxo não metabolizado, regulou positivamente a UCP-3 em miotubos L6. Já a alimentação junto com a administração de metilpalmoxirato (um inibidor da carnitina que impede a entrada do AGL na mitocôndria e, conseqüentemente, aumenta o AGL no sangue) preveniu a regulação negativa do RNAm da UCP-3 (29). Essas descobertas levam os autores a sugerirem que o acúmulo de ácidos graxos ou acetil-CoA intracelular pode ativar os PPAR, que regulam positivamente a expressão da UCP-3 (28).

Em resumo, o aumento da expressão da UCP-3 no músculo esquelético induzido pelo jejum leva a incerteza quanto ao papel desta proteína como um mediador da termogênese e, para mensurar o impacto da UCP-3 no gasto de energia, futuros estudos deveriam verificar a possibilidade da UCP-3 ter um papel direto no metabolismo de AGL pelos músculos durante o jejum.

\section{Metabolismo da glicose, exercício físico e UCP-3}

Assim como acontece com os ácidos graxos, é possível que o aumento na entrada de glicose no músculo esquelético resulte num aumento da UCP-3. O exercício físico consome grande quantidade de ATP dos músculos esqueléticos, e os ácidos graxos e a glicose são utilizados para fornecer esta energia. Alguns pesquisadores relatam que ratos exercitados por duas semanas ou em um único turno de natação apresentaram aumento de 14-18 vezes do RNAm da UCP-3 em músculos esqueléticos 3 horas após a última natação (28). Entretanto, 22 horas após o exercício, quando a glicose retornou à sua concentração normal, a concentração do RNAm da UCP-3 no músculo esquelético voltou a ficar semelhante à da condição sedentária (28).

O aumento da expressão do transportador de glicose (GLUT-4) no músculo esquelético e no tecido adiposo resulta em um aumento do fluxo de glicose intracelular nestes tecidos e melhora a tolerância da glicose em todo o corpo. De acordo com alguns autores, o RNAm da UCP-3 e GLUT-4 no músculo esquelético de ratos aumentou duas a três vezes entre 6 e 24 horas de exposição ao frio e diminuiu $50 \%$ do valor controle depois de seis dias no frio. Além disso, relataram que a concentração do RNAm da UCP-3 no músculo esquelético de pacientes diabéticos não dependentes de insulina (NIDDM) foi menor do que em sujeitos controle. Eles também observaram correlação positiva entre a expressão da UCP-3 em músculos esqueléticos e a utilização da glicose mediada pela insulina em indivíduos NIDDM. Estas observações levam a sugerir que o aumento da entrada de glicose no músculo resulta em aumento da expressão da UCP-3, que leva ao aumento no gasto de energia (30). Em conclusão, a superexpressão do GLUT-4 leva à regulação positiva do RNAm da UCP-3 no músculo esquelético, indicando que, em adição aos ácidos graxos, aumento no influxo de glicose pode regular o RNAm da UCP-3, e sugerindo que as mudanças na utilização dos dois substratos, no fluxo através do ciclo do ácido tricarboxílico e na produção de ATP podem estar relacionados com a regulação positiva do RNAm da UCP-3.

Em 1998, alguns pesquisadores mediram a concentração do RNAm da UCP-3 nos músculos tibial anterior e sóleo de ratos treinados por oito semanas, depois que estes se recuperaram da última sessão de exercícios. Os resultados mostraram que o treinamento de resistência reduz consideravelmente a concentração do RNAm da UCP-2 e UCP-3 em ambos os músculos (tibial anterior e sóleo). Diminuição na expressão da UCP no músculo esquelético favorece o armazenamento de energia durante a fase de recuperação e permite maior capacidade para executar trabalho mecânico durante exercícios subseqüentes. O efeito do treinamento na expressão do RNAm da UCP-2 e UCP-3 foi mais significativo no músculo tibial anterior (fibras de contração rápida, tipo IIa e IIb) em comparação ao músculo sóleo (fibras de contração 
lenta, tipo I), o que leva a sugerir que os músculos que dependem mais de glicose do que da oxidação de ácidos graxos para seu fornecimento de ATP ganham maior eficiência energética com o treinamento (31).

\section{Outros moduladores da UCP-3}

\section{Agonistas $\beta$-adrenérgicos}

$\mathrm{O}$ adrenoceptor $\beta 3$ não é expresso em concentrações significantes no músculo esquelético e TAM de roedores. Contudo, a administração de agonistas adrenérgicos in vivo tem demonstrado afetar a expressão do RNAm da UCP-3 nesses tecidos (9). Trinta horas após administração do agonista $\beta$-adrenérgico RO 16-8714, verificou-se aumento da expressão do RNAm da UCP-3 no TAM em ratos Zucker obesos, e o tratamento crônico com o agonista $\beta 3$ BRL 35135 também aumentou a expressão do RNAm no TAM de ratos Zucker obesos (9). Resultados similares foram obtidos com CL 316,243 usando camundongos hiperglicêmicos. No entanto, outros pesquisadores não observaram nenhum efeito agudo no tratamento com CL 316,243 na expressão do RNAm da UCP-3 no TAM (32).

Os efeitos observados com a administração de BRL 35135 consistiram em aumento da expressão do RNAm da UCP-3 no músculo sóleo de ratos Zucker magros e nenhuma mudança significativa em obesos. $O$ fato do BRL 35135 não estimular a expressão da UCP-3 no músculo de ratos Zucker obesos e estimular em ratos magros pode indicar que a obesidade leva à resistência do atípico adrenoceptor $\beta$ muscular para agonistas específicos (9).

\section{Insulina e leptina}

Pedersen e cols. (33) realizaram estudo in vitro com o músculo extensor digitório longo (EDL) sob estímulo da insulina, e observaram aumento de 2 vezes da expressão gênica do RNAm da UCP-3. Encontraram, ainda, resultados semelhantes com a estimulação elétrica e com o uso da droga 5-aminoimidazole-4-carboximida-ribosídeo (AICAR), um ativador da proteína quinase ativada por AMP (AMPK), e observaram que o aumento do RNAm da UCP-3 não dependia da captação de glicose, concluindo que a ativação da AMPK é a via comum para ação da insulina e contração muscular sobre a expressão da UCP-3.

Em ratos diabéticos, observou-se diminuição e aumento na expressão do RNAm da UCP-3 no TAM e no músculo gastrocnêmio, respectivamente (34). O tratamento com insulina, por outro lado, restabeleceu a expressão normal da UCP-3 em ambos os tecidos. Não está completamente claro se a insulina exerce ou não um efeito inibitório direto na expressão da UCP-3 no músculo esquelético. Em ratos diabéticos, o efeito da falta de insulina pode ser uma via indireta para aumentar os ácidos graxos livres na circulação, sendo estes os reguladores da UCP-3.

Em pacientes humanos, os resultados que poderiam ajudar a compreender os efeitos da insulina na expressão da UCP-3 do músculo esquelético são contraditórios. Em NIDDM, existem relatos de diminuição (35) e aumento na expressão da UCP-3 no músculo vasto lateral (10). Portanto, outros estudos são definitivamente necessários para responder a questão da direção dos efeitos da insulina na expressão da UCP-3 no músculo esquelético.

A leptina está relacionada ao controle do peso corporal por meio da regulação da homestase energética (36). Com a administração da leptina, observa-se aumento de $62 \%$ na expressão da UCP-3 no TAM de ratos (37) e também prevenção de sua diminuição induzida pela restrição alimentar em ambos TAM e músculo esquelético (13).

\section{Triiodotironina $\left(\mathrm{T}_{3}\right)$}

$\mathrm{O}$ hormônio da tireóide $\left(\mathrm{T}_{3}\right)$ tem como principal função aumentar a taxa metabólica e o dispêndio de energia. Estudo sobre sua ação nas células de roedores demonstrou aumento da respiração mitocondrial e promoção do desacoplamento entre o consumo de oxigênio e a síntese de ATP (38). Os efeitos do $\mathrm{T}_{3}$ que podem contribuir para termogênese são a ativação da bomba de $\mathrm{Na}^{+} / \mathrm{K}^{+}$, ativação de ciclos de substratos, biogênese mitocondrial e estimulação da expressão gênica e ativação das UCP-1 e UCP-3 (39). Estudos com camundongos, ratos e humanos demonstram haver correlação positiva entre a concentração de $\mathrm{T}_{3}$ e a expressão gênica do RNAm da UCP-3 em músculo esquelético $(38,40,41)$.

$\mathrm{A}$ administração de dose única do $\mathrm{T}_{3}$ em ratos hipotireóideos provocou aumento progressivo na UCP-3 no músculo gastrocnêmio (até 12 vezes) e na taxa metabólica de repouso (até 45\%) 65 horas após a injeção. Paralelamente, observou-se diminuição da taxa de fosforilação $(40 \%)$ e do potencial de membrana (8\%) mitocondrial (42). A administração do hormônio da tireóide $\left(\mathrm{T}_{3}\right)$ durante três dias em roedores provoca aumento da expressão de ambas as UCP-2 e UCP-3 no músculo esquelético, e isto poderia representar, em parte, um mecanismo pelo qual o $\mathrm{T}_{3}$ aumenta a taxa metabólica. Certamente, o efeito de aumento da taxa metabólica pelo $T_{3}$ não é totalmente dependente da estimulação das UCPs, já que camundongos transgênicos com deleção do gene que codifica a UCP-3 continuam respondendo normalmente ao hormônio (43). 


\section{CONSIDERAÇŌES FINAIS}

Consideradas descobertas relevantes, a clonagem da UCP-2 e UCP-3 nos tecidos adiposo e muscular esquelético tem produzido entusiasmo considerável devido à proporção destes em relação ao peso corporal e à possibilidade de que possam atuar como a UCP-1 do TAM, mediando a termogênese adaptativa e controlando o peso corporal. A regulação da expressão gênica e ativação da UCP-2 e UCP-3, bem como a real relevância delas entre os mecanismos de controle do peso corporal, ainda carecem de melhor definição, porém, a compreensão de sua regulação pode levar a novas e mais eficientes terapias, inclusive com o desenvolvimento de drogas destinadas a facilitar a oxidação de gorduras e o gasto de energia.

\section{REFERÊNCIAS}

1. Cortright RN, Zheng D, Jones JP, Fluckey JD, Dicarlo SE, Grujic D, et al. Regulation of skeletal muscle UCP-2 and UCP-3 gene expression by exercise and denervation. Am J Physiol 1999;276:E217-E21.

2. Ricquier D, Kader JC. Mitochondrial protein alteration in active brown fat: a sodium-dodecyl sulfatepolyarylamide gel eletrophoretic study. Biochem Biophys Res Commun 1976;73:577-83.

3. Boivin M, Camirand A, Carli F, Hoffer LJ, Silva JE. Uncoupling protein-2 and -3 messenger ribonucleic acids in adipose tissue and skeletal muscle of healthy males: variability, factors affecting expression, and relation to measures of metabolic rate. J Clin Endocrinol Metab 2000;85:1875-83.

4. Klingenberg $M$. Uncoupling protein - A useful energy dissipater. J Bioenerg Biomembr 1999;31:419-30.

5. Dulloo AG, Samec S. Uncoupling proteins: do they have a role in body weight regulation? News Physiol Sci 2000;15:313-8.

6. Boss O, Samec S, Paoloni-Giacobino A, Rossier C, Dulloo A, Seydoux J, et al. Uncoupling protein-3: a new member of the mitochondrial carrier family with tissuespecific expression. FEBS Lett 1997;408:39-42.

7. Gimeno RE, Dembski M, Weng X, Deng N, Shyjan AW, Gimeno CJ, et al. Cloning and characterization of an uncoupling protein homologue. Diabetes 1997;46:900-6

8. Yoshitomi H, Yamazaki K, Abe S, Tanaka I. Differential regulation of mouse uncoupling proteins among brown adipose tissue, white adipose tissue, and skeletal muscle in chronic b3 adrenergic receptor agonist treatment. Biochem Biophys Res Commun 1998;253:85-91.

9. Muzzin P, Boss O, Giacobino JP. Uncoupling Protein 3: its possible biological role and mode of regulation in rodents and humans. J Bioenerg Biomembr 1999;31:467-73.

10. Bao S, Kennedy A, Wojciechowski B, Wallace P, Ganaway E, Garvey WT. Expression of mRNAs encoding uncoupling proteins in human skeletal muscle. Effects of obesity and diabetes. Diabetes 1998; $47: 1935-40$.

11. Vidal-Puig A, Solanes G, Grujic D, Flier JS, Lowell BB. UCP-3: an uncoupling protein homologue expressed preferentially and abundantly in skeletal muscle and brown adipose tissue. Biochem Biophys Res Commun 1997;235:79-82.

12. Nordfors L, Hoffstedt J, Nyberg B, Thörne A, Arner P, Schalling $M$, et al. Reduced gene expression of UCP-2 but not UCP-3 in skeletal muscle of human obese subjects. Diabetologia 1998;41:935-9.

13. Boss $O$, Hagen $T$, Lowell BB. Uncoupling proteins 2 and 3. Potential regulators of mitochondrial energy metabolism. Diabetes 2000;49:143-56.

14. Ricquier D, Bouillaud $F$. The uncoupling protein homologues: UCP-1, UCP-2, UCP-3, StUCP and AtUCP. Biochem J 2000;345: 161-79.

15. Solanes G, Vidal-Puig A, Grujic D, Flier JS, Lowell BB. The human uncoupling protein-3 gene. Genomic structure, chromosomal localization, and genetic basis for short and long form transcripts. J Biol Chem 1997;41:25433-6.

16. Ricquier D, Bouillaud F. Mitochondrial uncoupling proteins: from mitochondria to the regulation of energy balance. J Physiol 2000;529/1:3-10.

17. Schrauwen $P$, Walder $K$, Ravussin $E$. Human uncoupling proteins and obesity. Obes Res 1999;7:97-105.

18. Diehl AM, Hoek JB. Mitochondrial uncoupling: role of uncoupling protein anion carriers and relationship to thermogenesis and weight control "The benefits of losing control". J Bioenerg Biomembr 1999;31:493-506.

19. Boss O, Samec S, Kuhne F, Bijlenga P, AssimacopoulosJeannet $F$, Seydoux J, et al. Uncoupling protein-3 expression in rodent skeletal muscle is modulated by food intake but not by changes in environmental temperature. J Biol Chem 1998;273:5-8.

20. Lin B, Coughlin S, Pileh PF. Bi-directional regulation of uncoupling protein-3 and GLUT-4 mRNA in skeletal muscle by cold. Am J Physiol 1998;275:E386-E91.

21. Margareto J, Marti A, Martínez JA. Changes in UCP mRNA expression levels in brown adipose tissue and skeletal muscle after feeding a high-energy diet and relationships with leptin, glucose and PPAR $\gamma$. J Nutr Biochem 2001;12:130-7.

22. Bachman ES, Dhillon H, Zhang C-Y, Cinti S, Bianco AC, Kobilka $B K$, et al. $\beta A R$ signaling required for dietinduced thermogenesis and obesity resistance. Science 2002;297:843-5.

23. Levile JA, Eberhardt NL, Jensen MD. Role of nonexercise activity thermogenesis in resistance to fat gain in humans. Science 1999;283:212-4. 
24. de Meis L. Uncoupled ATPase activity and heat production by the sarcoplasmic reticulum $\mathrm{Ca}^{2+}$-ATPase. J Biol Chem 2001;276:25078-87.

25. Kubo H, Libonati JR, Kendrick ZV, Paolone A, Gaughan JP, Houser SR. Differential effects of exercise training on skeletal muscle SERCA gene expression. Med Sci Sports Exerc 2003;35:27-31.

26. Weigle DS, Selfridge LE, Scwartz MW, Seeley RJ, Cummings DE, Havel PJ, et al. Elevated free fatty acids induce uncoupling protein 3 expression in muscle. A potential explanation for the effect of fasting. Diabetes 1998;47:298-302.

27. Millet L, Vidal H, Andreelli F, Larrouy D, Riou JP, Ricquier $D$, et al. Increased uncoupling protein-2 and -3 m RNA expression during fasting in obese and lean humans. J Clin Invest 1997; 100:2665-70.

28. Tsuboyama-Kasaoka N, Ezaki O. Mitochondrial uncoupling protein 3 in skeletal muscle. Front Biosc $2001 ; 6: 570-4$

29. Nagase I, Yoshida S, Canas X, Trie Y, Kimura Ki, Yoshida T, et al. Up-regulation of uncoupling protein 3 by thyroid hormone, peroxisome proliferatoractivated receptor ligands and 9-cis retinoic acid in L6 myotubes. FEBS Lett 1999;461:319-22.

30. Tsuboyama-Kasaoka N, Tsunoda N, Maruyama K, Takahashi M, Kim H, Cooke DW, et al. Overexpression of GLUT4 in mice causes up-regulation of UCP3 mRNA in skeletal muscle. Biochem Biophys Res Commun 1999;258: 187-93.

31. Boss O, Samec S, Desplanches D, Mayet MH, Seydoux $J$, Muzzin $P$, et al. Effect of endurance training on mRNA expression of uncoupling proteins 1,2 , and 3 in the rat. FASEB J 1998; 12:335-9.

32. Gong DW, He Y, Karas M, Reitman M. Uncoupling protein-3 is a mediator of thermogenesis regulated by thyroid hormone, beta-3-adrenergic agonists, and leptin. J Biol Chem 1997;272:24129-32.

33. Pedersen SB, Lund S, Buhl ES, Richelsen B. Insulin and contraction directly stimulate UCP2 and UCP3 mRNA expression in rat skeletal muscle in vitro. Biochem Biophys Res Commun 2001;283:19-25.

34. Kageyama H, Suga A, Kashiba M, Oka J, Osaka, T, Kashiwa T, et al. Increased uncoupling protein-2 and -3 gene expression in skeletal muscle of STZ-induced diabetic rats. FEBS Lett 1998;440:450-3.

35. Krook A, Digby J, O'Rahilly S, Zierath JR, WallbergHenriksson $H$. Uncoupling protein 3 is reduced in skeletal muscle of NIDDM patients. Diabetes 1998;47:1528-31.

36. Brabant G, Horn R, von zur Muhlen A, Mayr B, Wurster $U$, Heidenreich $F$, et al. Free and protein bound leptin are distinct and independently controlled factors in energy regulation. Diabetologia 2000;43:438-42.

37. Scarpace PJ, Nicolson M, Matheny M. UCP2, UCP3 and leptin gene expression: modulation by food restriction and leptin. J Endocrinol 1998;159:349-57.

38. Barbe P, Larrouy D, Boulanger C, Chevillotte E, Viguerie $N$, Thalamas $C$, et al. Triiodothyroninemediated up-regulation of UCP-2 and UCP-3 mRNA expression in human skeletal muscle without coordinated induction of mitochondrial respiratory chain genes. FASEB J 2001;15:13-5.

39. Freake HC, Oppenheimer JH. The thermogenic effect of thyroid hormone and its clinical implications. Ann Intern Med 2003;139:205-13.

40. Jekabsons MB, Gregoire FM, Schonfeld-Warden NA, Warden $\mathrm{CH}$, Horwitz BA. $\mathrm{T}_{3}$ stimulates resting metabolism and UCP-2 and UCP-3 mRNA but not nonphosphorylating mitochondrial respiration in mice. Am J Physiol 1999;277:E380-E9.

41. Cusin I, Rouru J, Visser T, Burger AG, RohnerJeanrenaud $F$. Involvement of thyroid hormones in the effect of intracerebroventricular leptin infusion on uncoupling protein-3 expression in rat muscle. Diabetes 2000:49:1101-5.

42. de Lange $P$, Lanni $A$, Beneduce $L$, Moreno $M$, Lombardi $A$, Silvestri $E$, et al. Uncoupling protein-3 is a molecular determinant for the regulation of resting metabolic rate by thyroid hormone. Endocrinology $2001 ; 142: 3414-20$

43. Lebon V, Dufour S, Petersen KF, Ren J, Jucker BM, Slezak LA, et al. Effect of triiodothyronine on mitochondrial energy coupling in human skeletal muscle. J Cin Invest 2001;108:733-7.

\section{Endereço para correspondência:}

Jair Rodrigues Garcia Júnior

Pró-Reitoria de Pesquisa e Pós-Graduação, UNOESTE

Rod. Raposo Tavares, Km 572 - Limoeiro

19067-175 Presidente Prudente, SP

Fax: (18) 229-2080

e.mail: jgjunior@posgrad.unoeste.br 